\title{
Sources of the Great Moderation: A Time-Series Analysis of GDP
}

\author{
Subsectors $^{\S}$ \\ Walter Enders ${ }^{\mathrm{a}}$, Jun $\mathrm{Ma}^{\mathrm{a}, *}$ \\ ${ }^{\text {a }}$ University of Alabama, Department of Economics, Finance and Legal Studies, Tuscaloosa, AL 35487, USA
}

\begin{abstract}
Recent work finds evidence that the volatility of the U.S. economy fell dramatically around the first quarter of 1984. We trace the timing of this so-called "Great Moderation" across many subsectors of the economy in order to better understand its root cause. We find that the interest rate sensitive sectors generally experience a much earlier volatility decline than other large sectors of the economy. The changes in Federal Reserve stabilization policies that occurred during the early 1980s support the view that improved monetary policy played an important role in stabilizing real economic activity. We find only mild evidence that "good luck" was important and little evidence to support the claim that improved inventory management was important.
\end{abstract}

\section{JEL classification: C12, C22, E5}

Keywords: volatility reduction, endogenous break, Markov regime-switching, monetary policy

\footnotetext{
$\S$ The authors wish to thank seminar participants at the University of Alabama, 2008 conference of Southern Economic Association, 2009 conference of the society for Studies in Nonlinear Dynamics and Econometrics for helpful comments. Jun Ma gratefully acknowledges financial support from the summer research program of Culverhouse College of Commerce \& Business Administration at the University of Alabama.

${ }^{*}$ Corresponding author.

Email addresses: wenders@,cba.ua.edu (Walter Enders),jma@cba.ua.edu (Jun Ma).
} 


\section{Introduction}

Recent work finds evidence that the volatility of the U.S. economy fell dramatically in the mid-1980s. Kim and Nelson (1999a), McConnell and Quiros (2000) and Blanchard and Simon (2001) are among the first to recognize and analyze this phenomenon. Stock and Watson (2002) report that the standard deviation of real U.S. GDP growth during the $1984-2002$ period was $61 \%$ smaller than that during the $1960-1983$ period. Moreover, the volatility reduction seems to be wide-spread in that the growth rates of many macroeconomic variables stabilized during the 1980s. A number of papers call this phenomenon the "Great Moderation" and set the timing of the reduction in early $1984 .^{1}$

Despite abundant evidence documenting the Great Moderation, the debate remains open regarding the root cause of the stabilization. The existing literature has largely focused on three possible explanations: good luck, improved monetary policy, and technological change. The essence of the "good luck" argument is that the macroeconomy experienced a relatively small number of large shocks since the 1980s. For example, Blanchard and Simon (2001) estimate the growth rate of real GDP $\left(\Delta y_{t}\right)$ as the $\operatorname{AR}(1)$ process: $\Delta y_{t}-\mu=\phi_{1}\left(y_{t-1}-\mu\right)+\varepsilon_{t}$ which implies $\operatorname{Var}(\Delta y)=\operatorname{Var}(\varepsilon) /\left(1-\phi_{1}^{2}\right)$. They find a significant decline in $\operatorname{Var}(\varepsilon)$ but do not find a change in the propagation parameter $\phi_{1}$. Similarly, Stock and Watson (2002) find that real GDP growth in a number of other countries stabilized at roughly the same time as the U.S. economy. As such, they conclude that “... monetary policy can take credit for only a small fraction of the great moderation." Instead, they argue that a fortuitous decrease in the size of the common international shocks accounts for the volatility reductions in the G7 countries. The counterfactual

\footnotetext{
${ }^{1}$ Also see McConnell, Mosser and Quiros (1999), Chauvet and Potter (2001), Sensier and van Dijk (2004), and Kim, Nelson and Piger (2004).
} 
analyses conducted by Ahmed, Levin and Wilson (2004), and Kim, Morley and Piger (2008) further strengthen the impression that the stabilization of U.S. economy was due to good luck in the sense that smaller and less frequent shocks hit the economy.

Bernanke (2004) argues that a better monetary environment has stabilized inflationary expectations and mitigated price level fluctuations. In such an environment, the Federal Reserve is better able to influence economic activity and the economy is better able to absorb outside shocks. In a slightly different vein, Romer (1999) constructs very long time series of several measures of aggregate U.S. output and shows that the frequency and duration of recessions have declined while the duration of expansions has increased. As such, she argues that better demand management policies have acted to mitigate downturns in the economy and, hence, to stabilize real GDP. Ramey and Vine (2004) study the behavior of U.S. automobile industry and their finding implies that monetary policy may be the key to understanding the volatility reduction of the aggregate economy. Similarly, Gali and Gambetti (2009) find that better monetary policy can explain the changing pattern in the comovements among output, hours and labor productivity.

The notion that improved technology has resulted in a more stable economy has been championed by McConnell and Quiros (2000) and Kahn, McConnell and Quiros (2002). Using somewhat disaggregated data, they trace the Great Moderation to a reduction in the production of durable goods but not in the sales of durables. As such, they argue that better inventory management (due to better technology) best explains the Great Moderation.

In this paper, we take the view that it is not credible to argue that the volatility reduction occurred in all sectors of the economy simultaneously. In this regard our paper is complementary to that of Owyang, Piger, and Wall (2008) who look at the timing of the Great Moderation across states and that of Irvine and Schuh (2007) who look at various 2-digit SIC manufacturing and 
trade industries. However, we differ from these papers in that we measure the timing and magnitudes of the volatility reductions in highly disaggregated subsectors of the economy. Although such measurement is interesting for its own sake, our ultimate aim is to provide some indirect evidence regarding the causes of the Great Moderation. For example, improvements in monetary policy are likely to affect the interest rate sensitive sectors, such as Residential investment, before any effects are realized in the services sector.

The five panels of Figure 1 suggest that the volatility reduction did not occur uniformly across all sectors of the economy. Note that Residential investment and the Exports of goods seem to experience volatility reductions earlier than the Services and Durable goods sectors. Using more formal techniques, we find that the volatility in a number of important interest rate sensitive sectors declined prior to $1984: 1$. There was also an early and sizable volatility reduction in the Exports of goods, but not in the Exports of services or in any of the import sectors. Moreover, many sectors that one would think are inventory-sensitive did not experience any significant volatility changes surrounding 1984:1; in fact, the Change in private inventories shows an (insignificant) increase of volatility in the early 1980s. It is possible that the volatility decline first occurred in the interest rate sensitive sectors and then spread out to the whole economy.

Even though a casual examination of the data suggests heterogeneous break dates, our aim is to formally estimate the timing and magnitudes of the breaks. The problem of finding volatility breaks is complicated by the fact that reduced volatility in one sector can "spill over" into other sectors. As such, it is important for us to try to pinpoint the volatility break dates as accurately as possible. Our problem is complicated by the fact that we are searching for a break in the variances (and not necessarily the levels) of the individual subsectors. As such, we use two 
different methods of detecting the timing of the volatility breaks in various subsectors of the U.S. economy. In Section 2, we describe how an $\operatorname{AR}(p)-\operatorname{ARCH}(q)$ model can be modified so as to estimate the break dates in volatility. Since inference in such a model is nonstandard, we develop a Monte Carlo procedure to show the significance of volatility breaks and the precision of the estimated break dates. Section 3 presents our key finding that some important interest rate sensitive sectors experienced a much earlier volatility decline than other large sectors of the economy. Moreover, the "good luck" view has mild support in that the Exports of goods (and two small components of government purchases) declined early. In addition to estimating the break dates, we follow Mankiw, Miron and Weil (1987) and calculate posterior odds ratios in order to measure the precision of the break dates. We compare these odds ratios to those obtained from Monte Carlo simulations. Section 4 provides further evidence on the timing of the volatility reduction for several important GDP subsectors based on a Markov regime-switching model. $^{2}$ Section 5 discusses the extent to which our findings are consistent with the proposed explanations for the Great Moderation.

\section{The General Methodology}

In this section, we describe a general methodology that can be used to detect a volatility break in a large number of sectors. To avoid being ad hoc, and potentially overfitting the data, we apply the identical methodology to each of the 51 different sectors and the 5 interest rate series examined in this paper. The method has the advantage that it is not residual-based in that the equations for the mean and the variance are simultaneously estimated using maximum

\footnotetext{
${ }^{2}$ In order to save space, we report only the results for six most important sectors. Results for all other sectors are available in the online Appendix to this paper.
} 
likelihood techniques. For now, we ignore the problem of estimating the appropriate lag lengths and consider a simple modification of a standard AR(1)-ARCH(1) model:

$$
\begin{gathered}
y_{t}=a_{0}+a_{1} y_{t-1}+\varepsilon_{t} ; \quad \varepsilon_{t} \sim N\left(0, h_{t}\right) \\
h_{t}=\alpha_{0}+\alpha_{1} \varepsilon_{t-1}^{2}+\gamma_{1} D_{t}
\end{gathered}
$$

where: $y_{t}=$ quarterly growth rate of output for the industry in question, $D_{t}=0$ if $t<t^{*}$ and $D_{t}=1$ otherwise, and $t^{*}$ is the break date. The parameter values are such that $-1<a_{1}<1, \alpha_{0}>0, \alpha_{1} \geq 0$, and $\alpha_{0}+\gamma_{1}>0$.

The important feature in (1) and (2) is that the conditional variance, $h_{t}$, is augmented by a structural break in the intercept term. The intercept of $h_{t}$ is $\alpha_{0}$ prior to $t^{*}$ and is $\alpha_{0}+\gamma_{1}$ beginning at $t^{*}$. Hence, if $\gamma_{1}$ is negative, there is a volatility reduction at $t^{*}$ equal to $-\gamma_{1}$ in the short-run and $-\gamma_{1} /\left(1-\alpha_{1}\right)$ in the long-run.

If the break date $t^{*}$ is known, it is possible to construct the variable $D_{t}$ and estimate (1) and (2) using standard maximum likelihood methods. Inference on the estimate of $\gamma_{1}$ can be conducted using a standard $t$-distribution. However, when we use actual economic data, the break dates are unknown so that a different methodology is necessary. A straightforward way to estimate $t^{*}$ is to use a grid search procedure to find the most likely break date. Stock and Watson (2002), for example, use Bai's (1997) asymptotic test and find very large confidence intervals surrounding the break dates. Instead, for each value of $t^{*}$ in the interval 1981:1 - 1986:4, we estimate a model in the form of (1) and (2). Although it would be possible for us to begin the search prior to 1981:1, it is highly unlikely that the cause of the Great Moderation began before 1981:1. Moreover, to our knowledge, no one has claimed that the source of the Great Moderation started as late as 1986:4. By restricting our search interval, we can impose prior knowledge so as to improve the precision of the estimated break dates. The use of a wider search interval results 
in overly large confidence intervals around the estimated break dates. Although other reasonable methods to find volatility breaks are available, this method has the advantage that it is easily applicable to all of the series we analyze below. The downside of the method is that the use of a grid search means that the usual $t$-statistic for the null hypothesis $\gamma_{1}=0$ does not have a standard distribution.

In order to obtain a reasonable idea of the distribution of $t$-statistic for the null hypothesis $\gamma_{1}=0$, we conducted a simple Monte Carlo experiment. Specifically, setting $\gamma_{1}=0$ and for various values of $a_{1}$ and $\alpha_{1}$, we generated 5000 Monte Carlo replications of (1) and (2) with $T=$ 151 observations corresponding to the number of observations in our data set. Every generated series was estimated for each value of $t^{*}$ in the interval analogous to the period running from 1981:1 to 1986:4. The value of $t^{*}$ yielding the greatest value of the likelihood function was designated as the most likely break date for that particular series. The $t$-statistic for the null hypothesis $\gamma_{1}=0$ was saved so that we have a total of $5000 t$-statistics for the null hypothesis $\gamma_{1}$ $=0$. Table 1 shows the upper and lower limits of the $t$-statistics that can be used to implement $10 \%, 5 \%$ and $1 \%$ tests for the null hypothesis $\gamma_{1}=0 .{ }^{3}$ Note that we report the upper and lower limits for combinations of $a_{1}$ and $\alpha_{1}$ such that $a_{1}=(0.0,0.1,0.2,0.3,0.4$, and 0.5$)$ and $\alpha_{1}=(0.0$, $0.2,0.4$, and 0.6). For example, given that $a_{1}=\alpha_{1}=0,95 \%$ of the $t$-statistics fell within the interval -2.115 to 2.686 .

Notice that the quantile intervals of the $t$-statistic in Table 1 are wider than those from a standard $t$-distribution because we are searching for the break date. Since the interval 1981:1 to 1986:4 is near the early portion of the data set, the resulting quantile intervals are not symmetric around zero. The key points to note about the quantile intervals are that they are relatively

\footnotetext{
${ }^{3}$ Each confidence interval is constructed such that there are equal probabilities in each of the tails.
} 
insensitive to the values of $a_{1}$ and $\alpha_{1}$ in the data-generating process. As such, we can get a reasonable idea about the significance of the break using the values in the table corresponding to the estimated values of $a_{1}$ and $\alpha_{1}$. A more conservative approach is to use the $t$-statistics associated with the values of $a_{1}=\alpha_{1}=0$. This set of values gives the widest possible quantile intervals and is analogous to a supremum test. Hence, suppose that a researcher estimates a series generated by (1) and (2) and finds that the $t$-statistic for the null hypothesis $\gamma_{1}=0$ is -1.96 . As such, it would be reasonable to maintain that there is a break in the volatility of the series with $90 \%$ confidence, but not $95 \%$ confidence.

A second issue pertains to the accuracy of the estimation of the break dates. Since each break date will be estimated with error, we wanted to get a notion about the precision of our methodology in estimating $t^{*}$. As such, we performed a second Monte Carlo experiment. Specifically, we generated 2500 series in the form of (1) and (2) for various values of $a_{1}, \alpha_{1}$, and $\gamma_{1}$. The difference between this and the Monte Carlo experiment reported in Table 1 is that each generated series actually contains a break at the sample point corresponding to $t^{*}=1983: 1$ or 1984:1. The selection of $t^{*}=1984: 1$ is based on our finding that the most likely break date for the volatility reduction in real GDP growth is 1984:1. Alternatively, the selection of $t^{*}=1983: 1$ reflects the most likely break date for several important GDP subsectors as we shall see in the next section. In each case (i.e., $t^{*}=1983: 1$ and $\left.t^{*}=1984: 1\right)$, we estimated each generated series for all possible break dates in the interval 1981:1 to 1986:4 and recorded the break date providing the largest value of the likelihood function. The distribution of these estimated break dates can be used to show whether the estimated break date for any series is statistically different from a true break date of 1983:1 or of 1984:1. 
The results are shown in Table 2 for various values of $a_{1}, \alpha_{1}$ and break sizes. All of the series are constructed such that the intercept for the post-break volatility $\left(\alpha_{0}+\gamma_{1}\right)$ is unity. Hence, the first column in the table (labeled $-\gamma_{1}$ ) measures the break size relative to the postbreak intercept. Unfortunately, the results shown in the table are a bit disappointing in that the break dates for small volatility breaks are poorly estimated. For example, when the true break date is $1983: 1$ and for the case of $-\gamma_{1}=2$ and $a_{1}=\alpha_{1}=0,90 \%$ of the estimated break dates occurred within the 1981:1 - 1985:3 period and 95\% occurred within the 1981:1 - 1986:2 period. As such, for small volatility breaks, the precision of the estimated break date is poor. However, the dates for large breaks can be reasonably well estimated. For example, for $t^{*}=$ 1983:1, $a_{1}=\alpha_{1}=0$, and $-\gamma_{1}=5,90 \%$ of the estimated break dates occurred in the interval 1981:3 - 1984:1. Not surprisingly, the precision of the estimated date is largest when the ARCH effect is small and the persistence of autoregressive parameter $a_{1}$ is small. Nevertheless, the key point is that these Monte Carlo results yield a rough estimate of the confidence intervals for $\gamma_{1}$ and $t^{*}$ for the actual sectoral data analyzed below.

However, when we followed Mankiw, Miron and Weil (1987) and calculated the posterior odds ratios, we obtained a better measure of the precision of the estimated break dates. For each value of $\gamma, a_{1}, \alpha_{1}$ we ran 5000 simulations and calculated the odds ratios given that the true break dates occurred in 1984:1. Specifically, we assigned all dates within the search interval an equal probability of a volatility reduction, a priori. Hence, for this diffuse prior, the posterior odds ratio is approximately equal to the ratio of the likelihood values calculated over all possible break dates relative to the likelihood value at the estimated break date. The posterior odds ratio is a measure of the plausibility that the volatility reduction occurs at a date other than the estimated break date. The simulated odds ratios are reported in Table 3. For example, when the actual 
break date is 1984:1, $h_{2} / h_{1}=0.33, \alpha_{1}=0.3$, and $a_{1}=0.4$, the odds of finding break dates of 1982:1, 1983:1, and 1985:1 are 0.20, 0.39, and 0.25, respectively. Not surprisingly, the odds ratios are relatively insensitive to the persistence of the mean equation $\left(a_{1}\right)$. They are most favorable to finding the "correct" date when the break size is large (so that $h_{2} / h_{1}$ is small) and the volatility persistence $\left(\alpha_{1}\right)$ is small. There is an asymmetry in that the odds of finding break dates later than 1984:1 are generally small regardless of the magnitude of $\alpha_{1}$ and the break size. The key point is that the odds ratios are low for break dates below mid-1983.

\section{GDP Subsectors: Estimation Results and Discussion}

In this section, we obtain the estimates of most likely break dates for the various subcomponents of private sector spending. Unlike the simple AR(1)-ARCH(1) model discussed above, we need to estimate the lag lengths in the mean and conditional variance equations. Consider the following generalization of (1) and (2):

$$
\begin{aligned}
& y_{t}=a_{0}+\sum_{i=1}^{p} a_{i} y_{t-i}+\varepsilon_{t} \\
& h_{t}=\alpha_{0}+\alpha_{1} \varepsilon_{t-1}^{2}+\alpha_{2} \varepsilon_{t-2}^{2}+\gamma_{1} D_{t}
\end{aligned}
$$

Notice that the model of the mean has $p$ lags and that the model of the conditional variance has two lags. ${ }^{4}$ For each estimated series, we selected the lag length $p$ using the generalto-specific method. Beginning with a lag length of 5 , we estimated an equation in the form of (1'). If the value of $a_{p}$ was not significant at the $5 \%$ level, we re-estimated the model using $p-1$ lags. This procedure was repeated until the last lag was significant or we reached $p=0$.

\footnotetext{
${ }^{4}$ As in Hamilton and Susmel (1994), the ARCH effects are small once the break in the intercept of $h_{t}$ is controlled for. Also, Ma, Nelson and Startz (2007) show that inference in a GARCH model may be problematic because of spurious persistence in this circumstance.
} 
Conditional on this lag length, for each value of $t^{*}$ in the interval 1981:1 - 1986:4, we estimated $\left(1^{\prime}\right)$ and (2') as an $\mathrm{ARCH}(2)$ process. The value of $t^{*}$ yielding the largest value of the likelihood function was taken to be the consistent estimate of the break date. As for the model of the volatility, if $\alpha_{q}$ was not significant at the 5\% level, we reestimated the series as an $\operatorname{ARCH}(q-1)$ process for $q=2$ or $1 .^{5}$

\subsection{Private Sector Expenditures}

The results of the estimations for various categories of private spending are reported in Table 4. We use every one of the quarterly series in Table 1.5 .3 of the seasonally adjusted real GDP data set (in expanded detail) obtained from the website of the Bureau of Economic Analysis. ${ }^{6}$ Although earlier data is available, the sample period we use runs from the first quarter of 1970 to the third quarter of 2007. As such, we avoid the need to control for the possibility of multiple structural breaks and still have a reasonable number of usable observations for each of the pre-break periods.

Notice that for real GDP, the estimated break date is 1984:1. Since the estimated intercept term $\left(\alpha_{0}\right)$ is 1.339 and the estimated magnitude of the break $\left(\gamma_{1}\right)$ is -1.117 , it follows that the estimate of the post-break intercept $\left(\alpha_{0}+\gamma_{1}\right)$ is 0.222 . The $t$-statistic for the null hypothesis $\gamma_{1}=0$ is -4.732 . If we compare this value to the relevant "pseudo-critical value" from Table 1, it is clear that the implied volatility reduction is highly significant. ${ }^{7}$ This is true even if

\footnotetext{
${ }^{5}$ Diagnostic checking included looking for breaks in the mean and looking for any remaining volatility breaks using the CUSUM2 test. Details are available in the online Appendix to this paper.

${ }^{6}$ The series Change in private inventory is absent from the Table 1.5.3 but extracted from the Table 1.4.6.

${ }^{7}$ For real GDP the estimated values of $\alpha_{1}$ and $a_{1}$ are 0.0 and 0.25 , respectively. From Table 1 , if $\alpha_{1}=0.0$ and $a_{1}=$ 0.20 , the lower and upper critical values for a $95 \%$ confidence interval are -2.082 to 2.550 .
} 
the conservative supremum $97.5 \%$ confidence interval of -2.401 to 2.974 is used. As reported in column six of the table, the pre-break estimate of the mean level of volatility is about six times its post-break level (i.e., as shown in the table, the ratio of $\left.h_{2} / h_{1}=16.6 \%\right){ }^{8}$

The remaining portions of Table 4 examine the subcomponents of real GDP. The last column labeled by '\%” reports the percentage share of each examined subsector in GDP at the time 1984:1. As such, entries in this column give a rough idea about the contribution of each subcomponent to GDP since the sectoral shares are largely stable throughout the sample period. If we use the approximate critical values in Table 1, it is clear that Personal consumption expenditures (PCE), which constitutes nearly two-thirds of GDP, experience a significant volatility reduction (the $t$-statistic for the null hypothesis $\gamma_{1}=0$ is -3.292 ) in 1986:3. Although the volatility falls to $24.8 \%$ of its original level, the break occurs far later than that for real GDP volatility. If we examine the subcategories of PCE, it appears that Durable goods volatility falls at the same time as overall PCE volatility. Furthermore, within the Durable goods sector, the most relevant subsector appears to be the Motor vehicles and parts subsector which has a significantly volatility reduction of about $70 \%$ in $1986: 3$. The volatility of Nondurable goods is estimated to occur at the boundary of our search, 1981:1, so that it is quite possible that the volatility reduction of nondurables actually occurred prior to 1981:1. The source of the volatility reduction is the Food sector. Since the Food sector comprises about $12 \%$ of GDP, this volatility reduction gives some support to the "good luck" hypothesis. Nevertheless, even though the break is significant, the size of the break is small relative to the break in GDP. The volatility reduction in Services is estimated to occur in 1985:1. Among the subsectors of services, it appears that

\footnotetext{
${ }^{8}$ The estimates in column six report the estimated ratio of the post-break unconditional variance, $\left(\alpha_{0}+\gamma_{1}\right) /\left(1-\alpha_{1}-\right.$ $\left.\alpha_{2}\right)$ to the pre-break unconditional variance, $\alpha_{0} /\left(1-\alpha_{1}-\alpha_{2}\right)$.
} 
Housing services have a volatility decline as late as 1986:3. But interestingly, Medical care has a large volatility reduction as early as 1981:4. The point is that the volatility reduction of the whole economy is not likely to have occurred due to a reduction in Personal consumption expenditures. Most subsectors experienced a volatility reduction either as late as 1986:3 or a reduction far earlier than any of the standard explanations allow. Within the class of Durables, only "Other" seems to have a significant volatility break prior to $1984: 1$.

Next, we examine Gross private domestic investment (GPDI) and its subcomponents. Regarding the overall level of GPDI, the absolute value of the $t$-statistic for the null hypothesis $\gamma_{1}$ $=0$ is large relative to those in Table 1 and the magnitude of the reduction is sizable. The key point to note is that the volatility reduction in this sector was concurrent with that of GDP. The estimates of the subcomponents are such that the break in Fixed investment occurs at almost the same time as the break in GDP, whereas the reduction in Residential investment is estimated to occur at 1983:1. Relative to the entries in Table 1, Nonresidential investment seems to have had a marginally significant volatility reduction in 1983:4. Finally, contrary to the hypothesis of improved inventory management, the Change in private inventory did not experience a volatility reduction but instead an (insignificant) increase.

Exports of goods experienced a volatility reduction prior to 1984:1, but the break in the Export of services is estimated to occur in 1986:3. Volatility reductions in the Imports of goods and the Imports of services are estimated to have occurred in 1986:2 and 1986:3, respectively.

\subsection{Government Expenditures}

It is possible that the volatility reduction in GDP occurred because of a reduction in the volatility of government spending. Table 5 reports the results of our methodology applied to the various subcomponents of government spending. Notice that total government spending 
(Government consumption and gross investment) experienced a large volatility decline in 1985:4; far later than the slowdown in GDP volatility. At the Federal level, only National defense gross investment shows a large volatility reduction prior to 1984:1 in that the intercept term falls from 176.301 to 29.011 at 1981:2. The $t$-statistic for the null hypothesis $\gamma_{1}=0$ is quite large relative to those shown in Table 1. Otherwise, National defense consumption expenditures experienced a volatility increase in 1986:1 and none of the $t$-statistics on any of the other estimates of $\gamma_{1}$ appear to be statistically significant. Interestingly, Gross investment by state and local governments also experienced a large and significant volatility reduction in 1982:2. Thus, two components of government investment spending experienced a significant volatility reduction prior to $1984: 1$.

The GDP subsectors with "statistically significant" volatility reductions occurring within the interval 1981:2 - 1986:3 (so that the break does not occur on the boundary) are shown in Figure 2. Note that the quarter of the break is in parentheses. We compare only subsectors at the same level of disaggregation since larger sectors are simply the agglomeration of the smaller sectors. For example, we do not report the break for Fixed investment since we report the breaks for both Residential investment and Nonresidential investment.

\subsection{Posterior Odds Ratios}

We calculated the posterior odds ratios for a number of important sectors and reported these results in Table 6. For GDP, the estimated value of $h_{2} / h_{1}$ is $0.166, \sum \alpha_{i}=0$, and persistence (measured by $\sum a_{i}$ ) is 0.25 . Table 3 indicates that the odds of the actual break date being 1983:4 or 1983:3 are about 0.6 and 0.33 , respectively. For Durable goods, Table 4 indicates that $h_{2} / h_{1}=$ $0.358, \sum \alpha_{i}=0$, and $\sum a_{i}=0$. From Table 3 , if the true date were 1984:1, the odds of finding a break date as late as 1986:3 would not be very different from zero (for space consideration the 
table runs only through 1985:4). In contrast, for Residential investment, Table 4 indicates that $h_{2} / h_{1}=0.106, \sum \alpha_{i}=0.33$, and $\sum a_{i}=0.61$. As such, if the true break date is 1984:1, Table 3 indicates that the odds of finding a break date as early as $1983: 1$ would be about $17 \%$.

A visual inspection of Figure 2 along with the help of Table 6 clearly indicates two significantly different groups of the subsectors. One group appears to have had an earlier volatility decline during the period of 1981:4 to 1983:4. This group consists mainly of interest rate sensitive sectors: Other Durables, Residential investment and Nonresidential investment. In addition, National defense gross investment, and State and local gross investment experienced early volatility declines. The other group that seems to have had a much later volatility reduction near the end of 1986 includes various services and the import sectors.

\subsection{Interest Rate Volatility}

We applied the same methodology to the study of the key interest rates typically thought to be associated with Federal Reserve policy. Specifically, we obtained the federal funds rate, the 3-month T-bill rate, and the fixed maturity rate for 1-year, 3-year, and 10-year government bonds. Unlike the results in the previous section, we used the first-differences of the monthly values. ${ }^{9}$ Hence, our search interval consisted of the 84 monthly values running from 1981:1 1986:12.

As shown in Table 7, notice that the estimated break dates are all far in excess of the GDP volatility break date of 1984:1. The date of 1986:12 for the federal funds rate is at the upper end of the boundary. Also notice that the magnitudes of the breaks are all quite large relative to the estimated value for $\alpha_{0}$. For example, the intercept of the federal funds rate falls from 0.207 to

\footnotetext{
${ }^{9}$ Standard unit-root tests indicated that the interest series were best modeled as $I(1)$ processes. Moreover, as shown in Prodan (2008), it is very difficult to accurately estimate break dates in highly persistent data.
} 
0.018 (equaling $8.4 \%$ of its initial value). We repeated the exercise using interest rate spreads. Specifically, when we subtracted the federal funds rate from each of the longer-term rates, the estimated break dates were all on the boundary of 1986:12.

Unfortunately, there is no clear interpretation of these findings regarding the argument that the enhanced efficacy of monetary policy brought about the Great Moderation. It could be argued that the volatility of the interest sensitive sectors would mimic the volatility of interest rates. Given that interest rates stabilized post-1984:1, adherents of this view could claim that better monetary policy was not responsible for the Great Moderation. On the other hand, it could be argued that interest rates--particularly the federal funds rate--are tools of monetary policy. Large movements in interest rates might have been necessary to offset shocks present in the real economy. Once the real economy stabilized, further large swings in interest rates were unnecessary.

\section{Further Evidence Using a Markov Regime-Switching Model}

In order to provide additional evidence regarding our findings, we apply the Markov regime-switching model of Hamilton (1989), and Kim and Nelson (1999b) to all GDP subsectors. One advantage of this method is that it can easily estimate the switching probabilities so that the precision of the estimated break dates can be readily inferred. Moreover, the method

allows us to jointly estimate separate break dates for the mean and volatility equations. Consider the following setting-up:

$$
\begin{gathered}
(1-\phi(L))\left(y_{t}-\mu_{D_{t}}\right)=\varepsilon_{t} ; \varepsilon_{t} \sim N\left(0, \sigma_{D_{t}}^{2}\right) \\
\mu_{D_{t}}=\mu_{0} \cdot\left(1-D_{1 t}\right)+\mu_{1} \cdot D_{1 t} \\
\sigma_{D_{t}}^{2}=\sigma_{0}^{2} \cdot\left(1-D_{2 t}\right)+\sigma_{1}^{2} \cdot D_{2 t}
\end{gathered}
$$


where $y_{t}$ represents the growth rate for each of relevant GDP subsectors; $\phi(L)=\sum_{i=1}^{p} \phi_{i} L^{i}$ and the lag length $p$ is identified using the general-to-specific principle discussed in the above section; the dummy variables are such that $D_{i t}=0$ if $t<t_{i}^{*}$ and $D_{i t}=1$ otherwise; and the $t_{i}^{*}$ are the break dates. Hence, this model allows for a potential break in the mean growth rate as well as in the volatility process. Note that $\sigma_{0}^{2}$ is the variance before the break and that $\sigma_{1}^{2}$ is the variance after the break. If there is a volatility decline we should find $\sigma_{1}^{2}<\sigma_{0}^{2}$.

Following Chib (1998), we treat the $D_{i t}$ as discrete latent variables with the following transition probabilities to allow for, at most, one break:

$$
\begin{aligned}
& \operatorname{Pr}\left(D_{i t+1}=0 \mid D_{i t}=0\right)=q_{i} \\
& \operatorname{Pr}\left(D_{i t+1}=1 \mid D_{i t}=1\right)=1 \\
& 0<q_{i}<1
\end{aligned}
$$

We estimate such a regime-switching model for all sectors, but for space considerations report only the results for the growth rates of GDP, Residential investment, Nonresidential investment, Exports of goods, Motor vehicles and parts (MVP), and Housing services. ${ }^{10}$ The estimation is done using standard maximum likelihood techniques. ${ }^{11}$

In constructing the six panels of Figure 3, we used Kim's (1994) algorithm to obtain the smoothed probability of staying in the high volatility regime for each considered series. The

\footnotetext{
${ }^{10}$ The results for the other sectors are available in the online Appendix to this paper.

${ }^{11}$ Notice that we allow the break date for the mean to be distinct from the break date in the volatility by using two different state variables. We found that the changes in the mean were not statistically significant for all series except Recreation, Federal government consumption and gross investment, and National defense gross investment. As such, we report only results from the restricted model with no break in the mean. Details are provided in the online Appendix to this paper.
} 
shaded vertical line indicates the first date this probability falls below 0.5 . The sharp decline of this probability for Residential investment during the early 1980s adds to the evidence that this sector seems to have experienced an early volatility decline. On the other hand, the switching of the probability for Nonresidential investment seems to be much more gradual. The smoothed probability for both Exports of goods and Medical care show a sharp decline during the early 1980s. But for both MVP and Housing services, the probability of switching into the low volatility regime happens much later. Overall, the results based on the Markov regime-switching model further strengthen our findings in Section 3.

\section{Conclusion}

We presented strong evidence that the Great Moderation did not occur uniformly across the various sectors of the economy. Our findings seem to be consistent with the notion that better monetary policy played an important role in stabilizing economic activity across the sectors. We find only mild evidence that "good luck" was important and little evidence to support the claim that improved inventory management was important.

It is particularly interesting that various subcomponents of private sector investment (i.e., Residential and Nonresidential investment) declined prior to 1984:1. In contrast, the volatility declines of the services and import sectors generally occurred much later. This seems to be generally consistent with the arguments presented by Bullard and Singh (2008), Clarida, Gali and Gertler (2000) and Bernanke (2004) that better monetary policy helped to stabilize the economy. After all, monetary policy is most likely to affect the interest rate sensitive sectors. One possible explanation for the enhanced efficacy of monetary policy is that the relaxation of Regulation-Q in the early 1980s allowed Residential investment to respond more directly to changes in market interest rates. Moreover, as shown in papers such as Clarida, Gali, and Gertler 
(2000) and Bunzel and Enders (2010), under the stewardship of Paul Volcker, the Federal Reserve began to satisfy the so-called Taylor Principle. In this view, the conduct of monetary policy was enhanced as the Federal Reserve adjusted interest rates by more than one-to-one in response to deviations of the inflation rate from its target level.

It seems to be an anomaly that the volatility of MVP did not decline until 1986:3. It is generally agreed that this sector is quite responsive to interest rates. However, President Reagan's voluntary export restraints on Japanese automobiles went into effect in May 1981. Initially, only 1.68 million Japanese cars were allowed to enter the U.S. each year. The cap was raised to 1.85 million cars in 1984 , and to 2.30 million in 1985. It is possible that the relaxation of the restraints subjected U.S. automobile makers to more foreign competition and ultimately stabilized sales.

Overall, we find only mild support for the view that "good luck" helped to stabilize the economy. Oil intensive sectors--such as Electricity and gas, Transportation, and Gasoline, fuel oil, and other energy--did not experience any significant volatility reductions. Regarding other aspects of external stability, Exports of services, Imports of goods, and Imports of services did not stabilize until much later than 1984:1. Nevertheless, adherents to the "good luck" view can take solace in the fact that the Exports of goods experienced a volatility decline as early as 1982:4. This sector comprised about $8 \%$ of GDP and the post-break volatility fell to approximately $1 / 6$ of its pre-break level. The "good luck" argument also receives support in that two components of government purchases--National defense gross investment, and State and local government investment--seem to have stabilized prior to 1984:1. However, these sectors sum to about $2.8 \%$ of GDP, so that the total contribution is likely to have been small. 
We find little support for the notion that improved inventory management techniques were responsible for the Great Moderation. Transportation equipment, Industrial equipment, Other equipment, and MVP all use large inventories. Nevertheless, adherents to this view, such as McConnell and Quiros (2000), could argue that a complete examination of their argument requires a study of the volatility comovements across sectors. It is probably true that better inventory management practices have played an important role in these sectors. However, the important point is that we did not find early volatility reductions in those sectors generally deemed to rely most heavily on inventories. A direct study of the Change in private inventory even reveals an (insignificant) increase in its volatility. 


\section{References}

Ahmed, S., Levin, A., Wilson, B.A., 2004. Recent U.S. macroeconomic stability: good policy, good Practices, or good luck? Review of Economics and Statistics 86, 824-832.

Bai, J., 1997. Estimation of a change point in multiple regression models. Review of Economics and Statistics 79, 551-563.

Bernanke, B.S., 2004. The Great Moderation. Remarks at the meetings of the Eastern Economic Association, Washington, DC, federalreserve.gov/boarddocs/ speeches/2004/20040220. (last accessed March 6, 2010).

Blanchard, O., Simon, J., 2001. The long and large decline in U.S. output volatility. Brookings Papers on Economic Activity 0, 135-174.

Bullard, J. and Singh, A., 2008. Worldwide macroeconomics stability and monetary policy rules. Journal of Monetary Economics 55, S34-S47.

Bunzel, H., Enders, W., 2010. The Taylor rule and "opportunistic" monetary policy. Journal of Money, Credit and Banking 42, 931-949.

Chauvet. M., Potter, S., 2001. Recent changes in U.S. business cycles. Manchester School 69, 481-508.

Chib, S., 1998. Estimation and comparison of multiple change-point models. Journal of Econometrics 86, 221-241.

Clarida, R., Gali, J., Gertler, M., 2000. Monetary policy rules and macroeconomic stability: evidence and some theory. Quarterly Journal of Economics 115, 147-180.

Gali. J., Gambetti, L., 2009. On the sources of the Great Moderation. American Economic Journal: Macroeconomics 1, 26-57. 
Hamilton, J., 1989. A new approach to the economic analysis of nonstationary time series and the business cycle. Econometrica 57, 357-384.

Hamilton, J., Susmel, R., 1994. Autoregressive conditional heteroskedasticity and changes in regime. Journal of Econometrics 64, 307-333.

Irvine, F.O., Schuh, S., 2007. Interest sensitivity and volatility reductions: cross-section evidence. International Journal of Production Economics 108, 31-42.

Kahn, J.A., McConnell, M.M., Quiros, G.P., 2002. On the causes of the increased stability of the U.S. economy. Federal Reserve Board New York Economic Policy Review, May, 183-202.

Kim, C.-J., 1994. Dynamic linear models with markov-switching. Journal of Econometrics 60, 1 -22 .

Kim, C.-J., Nelson, C.R., 1999a. Has the U.S. economy become more stable? A Bayesian approach based on a Markov-Switching model of the business cycle. Review of Economics and Statistics 81, 608-616.

Kim, C.-J., Nelson, C.R., 1999b. State-Space Models with Regime Switching: Classical and Gibbs-Sampling Approaches with Applications. MIT Press, Cambridge.

Kim, C.-J., Nelson, C.R., Piger, J., 2004. The less volatile US economy: a Bayesian investigation of timing, breadth and potential explanations. Journal of Business and Economic Statistics $22,80-93$.

Kim, C.-J., Morley, J., Piger, J., 2008. Bayesian counterfactual analysis of the sources of the great moderation. Journal of Applied Econometrics 23, 173-191.

Ma, J., Nelson, C.R., Startz, R., 2007. Spurious inference in the GARCH(1,1) model when it is weakly identified. Studies in Nonlinear Dynamics \& Econometrics 11, Article 1. 
Mankiw, N.G., Miron, J.A., Weil, D.N., 1987. The adjustment of expectations to a change in regime: a study of the founding of the Federal Reserve. American Economic Review 77, $358-374$.

McConnell, M.M, Mosser, P., Quiros, G.P., 1999. A decomposition of the increased stability of GDP growth. Current Issues in Economics and Finance 5, 1-6.

McConnell, M.M., Quiros, G.P., 2000. Output fluctuations in the United States: what has changed since the early 1980s? American Economic Review 90, 1464-1476.

Owyang, M., Piger, J., Wall, H., 2008. A state-level analysis of the great moderation. Regional Science and Urban Economics 38, 578-589.

Prodan, R., 2008. Potential pitfalls in determining multiple structural changes with an application to purchasing power parity. Journal of Business and Economic Statistics 26, 50-65.

Ramey, V.A., Vine, D.J., 2004. Tracking the source of the decline in GDP volatility: an analysis of the automobile industry. NBER working paper No. 10384.

Romer, C., 1999. Changes in business cycles: evidence and explanations. Journal of Economic Perspectives 13, 23-44.

Sensier, M., van Dijk, D., 2004. Testing for volatility changes in U.S. macroeconomic time series. Review of Economics and Statistics 86, 833-839.

Stock, J.H., Watson, M.W., 2002. Has the business cycle changed and why? NBER working paper No.9127. 
Table 1: Confidence Intervals for the Null Hypothesis $\gamma_{1}=0$

\begin{tabular}{cccccccc}
\hline$a_{1}$ & $\alpha_{1}$ & $\mathrm{~L} 90 \%$ & $\mathrm{U} 90 \%$ & $\mathrm{~L} 95 \%$ & $\mathrm{U} 95 \%$ & $\mathrm{~L} 97.5$ & $\mathrm{U} 97.5$ \\
\hline 0.00 & 0.00 & -1.8715 & 2.381 & -2.115 & 2.686 & -2.401 & 2.974 \\
0.00 & 0.20 & -1.9094 & 2.277 & -2.146 & 2.545 & -2.348 & 2.858 \\
0.00 & 0.40 & -1.8860 & 2.292 & -2.131 & 2.553 & -2.345 & 2.866 \\
0.00 & 0.60 & -1.8929 & 2.311 & -2.125 & 2.557 & -2.341 & 2.879 \\
0.10 & 0.00 & -1.8303 & 2.312 & -2.099 & 2.571 & -2.312 & 2.899 \\
0.10 & 0.20 & -1.8714 & 2.279 & -2.128 & 2.520 & -2.298 & 2.816 \\
0.10 & 0.40 & -1.8613 & 2.266 & -2.100 & 2.543 & -2.257 & 2.788 \\
0.10 & 0.60 & -1.8575 & 2.254 & -2.116 & 2.529 & -2.292 & 2.836 \\
0.20 & 0.00 & -1.8602 & 2.269 & -2.082 & 2.550 & -2.259 & 2.772 \\
0.20 & 0.20 & -1.8622 & 2.210 & -2.072 & 2.479 & -2.239 & 2.776 \\
0.20 & 0.40 & -1.8539 & 2.210 & -2.075 & 2.495 & -2.233 & 2.820 \\
0.20 & 0.60 & -1.8456 & 2.220 & -2.068 & 2.506 & -2.241 & 2.783 \\
0.30 & 0.00 & -1.8541 & 2.211 & -2.065 & 2.484 & -2.276 & 2.752 \\
0.30 & 0.20 & -1.8398 & 2.226 & -2.070 & 2.503 & -2.239 & 2.755 \\
0.30 & 0.40 & -1.8243 & 2.215 & -2.051 & 2.489 & -2.219 & 2.747 \\
0.30 & 0.60 & -1.8280 & 2.221 & -2.055 & 2.490 & -2.230 & 2.713 \\
0.40 & 0.00 & -1.8782 & 2.155 & -2.069 & 2.457 & -2.284 & 2.722 \\
0.40 & 0.20 & -1.8254 & 2.200 & -2.031 & 2.472 & -2.195 & 2.755 \\
0.40 & 0.40 & -1.8235 & 2.201 & -2.017 & 2.469 & -2.181 & 2.738 \\
0.40 & 0.60 & -1.8099 & 2.180 & -2.017 & 2.484 & -2.180 & 2.741 \\
0.50 & 0.00 & -1.9005 & 2.110 & -2.101 & 2.397 & -2.282 & 2.631 \\
0.50 & 0.20 & -1.8130 & 2.204 & -2.002 & 2.459 & -2.192 & 2.753 \\
0.50 & 0.40 & -1.8011 & 2.187 & -1.975 & 2.461 & -2.139 & 2.678 \\
0.50 & 0.60 & -1.7792 & 2.188 & -1.981 & 2.441 & -2.131 & 2.718 \\
\hline
\end{tabular}


Table 2: Confidence Intervals for $t^{*}$

\begin{tabular}{|c|c|c|c|c|c|c|c|c|c|c|c|c|c|c|c|}
\hline \multirow[t]{2}{*}{$-\gamma_{1}$} & $h_{2} / h_{1}$ & & $A$ & L 90\% & U 90\% & I $95 \%$ & 年 & L 97.5 & J 97.5 & L 90\% & $\mathrm{U} 90^{\circ}$ & - & 年 & L 97.5 & U 97.5 \\
\hline & & & & \multicolumn{6}{|c|}{ Break Date $=$ 1983:1 } & \multicolumn{6}{|c|}{ Break Date $=$ 1984:1 } \\
\hline 2 & 0.33 & 0.0 & 0.0 & 1981:1 & $1985: 3$ & 1981:1 & $1986: 2$ & 1981:1 & $1986: 3$ & 1981:2 & $1985: 4$ & 1981:1 & $1986: 3$ & 1981:1 & 1986:4 \\
\hline 2 & 0.33 & & & & $85: 2$ & & $86: 1$ & & & & & & & 1981:1 & 1986:4 \\
\hline 2 & 0.33 & & & & $85: 2$ & & & & & & & & 1986:2 & 81:1 & $1986: 4$ \\
\hline 2 & & & & & & & & & & & & & & $81: 1$ & 1986:4 \\
\hline 2 & & & & & & & & & & & & & & & $986: 4$ \\
\hline 2 & 3 & 3 & & $: 1$ & $: 1$ & & 1986 & 1981:1 & & & 198 & & $6: 4$ & 1981:1 & 1986:4 \\
\hline 2 & & & & 81:1 & 1986:2 & 198 & 1986:4 & 1981:1 & & & 198 & $1: 1$ & $1986: 4$ & 1981:1 & 1986:4 \\
\hline 2 & & & & & & & & & & & & & & & $36: 4$ \\
\hline 2 & & & & & 2 & & $: 4$ & 1981 & & & & & & 1981:1 & 1986:4 \\
\hline 5 & & & & & & & & 198 & & & & & & 1981:2 & 1986:1 \\
\hline 5 & & & & & & & & & & & & & & & $986: 1$ \\
\hline 5 & 17 & & & & 1984:1 & & & 198 & & & & & & $1: 2$ & $1985: 4$ \\
\hline 5 & & & & & & & & & & & & & $6: 2$ & 1981:1 & $1986: 3$ \\
\hline 5 & & & & & & & & & & & & & & 81:1 & $1986: 3$ \\
\hline 5 & & & & & 1984:3 & & $1985: 3$ & 1981 & & & & & $6: 2$ & 1981:1 & $1986: 3$ \\
\hline 5 & & & & & $: 2$ & & & 1981:1 & & & & $1: 2$ & $1986: 2$ & 1981:1 & $1986: 4$ \\
\hline 5 & & & & & & & $86: 1$ & & & & & & $1986: 3$ & 1981:1 & 1986:4 \\
\hline 5 & & & & & 1985:2 & & $1985: 4$ & 1981:1 & & & & & 1986:2 & 1981:1 & $1986: 4$ \\
\hline 10 & & & & & & & & 1981:2 & & & & & $5: 1$ & 1982:1 & $1985: 2$ \\
\hline 10 & & & & & & & & & & & & $2: 3$ & $5: 1$ & $1982: 2$ & $1985: 2$ \\
\hline 10 & & 0.0 & & 1982:1 & 1983:4 & 1981:3 & 1984:1 & 1981:2 & $1984: 2$ & & & $1982: 3$ & 1984:4 & 1982:1 & $1985: 2$ \\
\hline 10 & 0.09 & & & & 1984:1 & 1981:3 & $1984: 3$ & 1981:1 & & & & $1982: 2$ & $1985: 3$ & 1981:4 & $1985: 4$ \\
\hline 10 & & & & & & & & & & & & $32: 2$ & & 1981:4 & $1985: 4$ \\
\hline 10 & & 0.3 & & & & & & & & & & & & 1981:4 & $1985: 4$ \\
\hline 10 & & 0.5 & & $981: 4$ & $1984: 3$ & 1981:2 & $1985: 2$ & 1981:1 & & & & 1982:1 & $1985: 4$ & $1981: 3$ & $1986: 2$ \\
\hline 10 & & & & & & & & & & & & & & 1981:2 & $1986: 2$ \\
\hline 10 & 0.09 & 0.5 & 0.6 & 1981:4 & $1984: 3$ & 1981:2 & 1985:1 & 1981:1 & $1985: 3$ & $1982: 3$ & $1985: 3$ & 1982:1 & $1985: 4$ & 1981:2 & $1986: 2$ \\
\hline
\end{tabular}


Table 3: Simulated Odds Ratios

\begin{tabular}{|c|c|c|c|c|c|c|c|c|c|c|c|c|c|c|c|c|c|c|c|}
\hline$-\gamma_{1}$ & $h_{2} / h_{1}$ & & $a_{1}$ & $2: 1$ & $2: 2$ & $2: 3$ & $2: 4$ & 83:1 & $3: 2$ & $3: 3$ & $83: 4$ & 84:1 & $34: 2$ & $84: 3$ & 84 & $85: 1$ & $35: 2$ & $5: 3$ & 1 \\
\hline 2 & 0.33 & & & & & & & & & & & & & & & & & & \\
\hline 2 & & & & & & & & & & & & & & & & & & & \\
\hline 2 & & & & 1 & & & & & & & .74 & & & & & & & & 10 \\
\hline 2 & & & & 19 & 3 & 26 & .35 & ( & 50 & .62 & 93 & & .54 & 0.36 & & .27 & 20 & & .18 \\
\hline 2 & & & & 0 & 23 & 26 & & & 49 & & 92 & & 52 & & & & & & .17 \\
\hline 2 & & & & 20 & 3 & 5 & & & & & & 80 & & 0.35 & & .25 & 20 & 22 & .17 \\
\hline 2 & & & & 25 & & & & & & & & & & 47 & & & & & .25 \\
\hline 2 & & & & & & & & & & & & & & & & & & & .25 \\
\hline 2 & & & & 24 & & & & & & & & 1. & & .42 & & & & & .24 \\
\hline 5 & & & & & & & & & & & & & & & & & & & .02 \\
\hline 5 & & & & & & & & & & & & ( & & & & & & & .03 \\
\hline 5 & & & & & & & & & & & & & & & & & & & .03 \\
\hline 5 & & & & & & & & & & & & & & & & & & & .06 \\
\hline 5 & & & & & & & & & & & & & & & & & & & .05 \\
\hline 5 & & & & & & & & & & & & & & & & & & & .05 \\
\hline 5 & & & & & & & & & & & & & & & & & & & .10 \\
\hline 5 & & & & & & & & & & & & & & & & & & & .09 \\
\hline 5 & & & & & & & & & & & & & & & & & & & .10 \\
\hline 10 & & & & & & & & & & & & & & & & & & & .01 \\
\hline 10 & & & & 01 & & & & & & & & & & & & 5 & & & .01 \\
\hline 10 & & & & & & & & & & & & & & & & & & & 0.01 \\
\hline 10 & & & & 02 & & & & & & & & & & & & & & & .02 \\
\hline 10 & & & & .03 & & & & & & & & 1. & & & & & & & .02 \\
\hline 10 & & & & & & & & & & & & & & & & & & & 0.02 \\
\hline 10 & & & & & & & & & & & & 1. & & & & & 09 & & .04 \\
\hline 10 & & & & & & & & & & & & & & & & & & & 0.05 \\
\hline 10 & 0.09 & 0.5 & 0.6 & 0.04 & 0.05 & 0.07 & 0.11 & 0.17 & 0.28 & 0.48 & 0.83 & 1.00 & 0.42 & 0.26 & 0.19 & 0.13 & 0.09 & 0.08 & 0.05 \\
\hline
\end{tabular}

Note that the break date used in all simulations was 1984:1. Moreover, the value of $a_{0}+\gamma_{1}$ was always set equal to unity. 
Table 4: Components of Private Sector Expenditures

\begin{tabular}{|c|c|c|c|c|c|c|c|c|}
\hline & Date & $\alpha_{0}$ & $\gamma_{1}$ & $t$-stat & $h_{2} / h_{1}$ & $\sum a_{i}$ & $\sum \alpha_{i}$ & $\%$ \\
\hline Gross domestic product & 1984:1 & 1.339 & -1.117 & -4.732 & 0.166 & 0.25 & 0.00 & 100 \\
\hline Personal consumption expenditures & $1986: 3$ & 0.662 & -0.498 & -3.292 & 0.248 & 0.49 & 0.00 & 62.7 \\
\hline Durable goods & $1986: 3$ & 16.138 & -10.368 & -2.631 & 0.358 & 0.00 & 0.00 & 8.1 \\
\hline Motor vehicles and parts & $1986: 3$ & 60.810 & -42.338 & -3.244 & 0.304 & -0.30 & 0.00 & 3.5 \\
\hline Furniture and household equip. & 1981:4 & 3.215 & -2.015 & -1.739 & 0.373 & 0.42 & 0.28 & 3.1 \\
\hline Other & $1982: 3$ & 6.332 & -4.582 & -2.716 & 0.276 & 0.00 & 0.55 & 1.5 \\
\hline Nondurable goods & 1981:1 & 0.760 & -0.512 & -3.045 & 0.326 & 0.37 & 0.00 & 24.9 \\
\hline Food & 1981:1 & 0.967 & -0.613 & -3.015 & 0.366 & 0.00 & 0.00 & 12.7 \\
\hline Clothing and shoes & $1984: 3$ & 2.035 & -0.923 & -2.006 & 0.547 & 0.00 & 0.24 & 3.8 \\
\hline Gasoline, fuel oil, \& other energy & 1981:1 & 6.559 & -4.737 & -1.463 & 0.278 & 0.00 & 0.00 & 3.7 \\
\hline Other & 1982:1 & 0.868 & -0.509 & -1.948 & 0.413 & 0.33 & 0.23 & 4.6 \\
\hline Services & $1985: 1$ & 0.202 & -0.140 & -2.964 & 0.308 & 0.33 & 0.29 & 29.7 \\
\hline Housing & $1986: 3$ & 0.098 & -0.048 & -2.217 & 0.505 & 0.68 & 0.00 & 9.0 \\
\hline Household operation & 1986:1 & 2.404 & -0.262 & -0.457 & 0.891 & -0.53 & 0.00 & 4.0 \\
\hline Electricity and gas & 1981:1 & 8.936 & -0.307 & -0.120 & 0.966 & -1.28 & 0.00 & 1.9 \\
\hline Other household operation & 1982:1 & 0.640 & -0.070 & -0.500 & 0.890 & 0.42 & 0.00 & 2.0 \\
\hline Transportation & 1986:1 & 1.628 & -1.284 & -1.814 & 0.211 & 0.56 & 0.47 & 2.3 \\
\hline Medical care & 1981:4 & 0.794 & -0.687 & -3.654 & 0.135 & 0.51 & 0.00 & 6.4 \\
\hline Recreation & 1983:1 & 0.935 & -0.366 & -1.946 & 0.609 & 0.30 & -0.06 & 1.5 \\
\hline Other & 1985:1 & 1.669 & -1.018 & -2.963 & 0.390 & 0.37 & 0.00 & 6.5 \\
\hline Gross private domestic investment & 1984:1 & 41.692 & -34.621 & -2.789 & 0.170 & 0.06 & 0.00 & 18.5 \\
\hline Fixed investment & 1983:4 & 6.692 & -4.684 & -2.838 & 0.300 & 0.52 & 0.00 & 18.2 \\
\hline Nonresidential & 1983:4 & 5.432 & -2.818 & -2.261 & 0.481 & 0.62 & 0.00 & 13.3 \\
\hline Structures & 1981:3 & 5.650 & 2.302 & 0.944 & 1.408 & 0.49 & 0.00 & 4.9 \\
\hline Equipment and software & 1984:1 & 8.267 & -4.446 & -2.699 & 0.462 & 0.55 & -0.07 & 8.4 \\
\hline Info. equipment and software & 1983:4 & 8.455 & -4.176 & -2.303 & 0.506 & 0.55 & 0.00 & 2.4 \\
\hline Computers and equipment & $1986: 3$ & 97.673 & -75.408 & -4.054 & 0.228 & 0.27 & 0.00 & 0.4 \\
\hline Software & 1983:1 & 5.273 & -2.339 & -1.542 & 0.557 & 0.58 & 0.00 & 0.3 \\
\hline Other & 1982:1 & 5.380 & 2.372 & 1.188 & 1.441 & 0.45 & 0.00 & 1.7 \\
\hline Industrial equipment & $1981: 3$ & 7.275 & -0.767 & -0.376 & 0.895 & 0.44 & -0.08 & 2.2 \\
\hline Transportation equipment & $1986: 3$ & 36.344 & -0.870 & -0.085 & 0.976 & 0.05 & 0.06 & 1.9 \\
\hline Other equipment & 1983:4 & 22.446 & -16.098 & -2.932 & 0.283 & 0.00 & 0.00 & 1.9 \\
\hline Residential & 1983:1 & 25.144 & -22.484 & -3.694 & 0.106 & 0.61 & 0.33 & 4.9 \\
\hline Change in private inventory & 1981:4 & 426.01 & 238.26 & 1.620 & 1.559 & 0.533 & 0 & 0.4 \\
\hline Exports & 1983:1 & 11.352 & -9.370 & -3.286 & 0.175 & 0.27 & 0.26 & 9.9 \\
\hline Goods & 1982:4 & 18.214 & -15.008 & -3.031 & 0.176 & 0.25 & 0.23 & 8.0 \\
\hline Services & $1986: 3$ & 14.481 & -8.898 & -2.074 & 0.386 & -0.23 & 0.00 & 1.9 \\
\hline Imports & $1985: 4$ & 14.614 & -12.707 & -4.050 & 0.130 & 0.22 & 0.24 & 11.2 \\
\hline Goods & 1986:2 & 17.417 & -14.979 & -3.465 & 0.140 & 0.00 & 0.28 & 9.5 \\
\hline Services & 1986:3 & 10.231 & -5.560 & -2.539 & 0.457 & 0.00 & 0.00 & 1.9 \\
\hline
\end{tabular}


Table 5: Components of Government Expenditures

\begin{tabular}{lcrrrcccc}
\hline & Date & \multicolumn{1}{c}{$\boldsymbol{\alpha}_{\mathbf{0}}$} & \multicolumn{1}{c}{$\boldsymbol{\gamma}_{\mathbf{1}}$} & $\boldsymbol{t}$-stat & $\boldsymbol{h}_{\mathbf{2}} / \boldsymbol{h}_{\mathbf{1}}$ & $\boldsymbol{\Sigma} \boldsymbol{a}_{\boldsymbol{i}}$ & $\boldsymbol{\Sigma} \boldsymbol{\alpha}_{\boldsymbol{i}}$ & $\boldsymbol{\%}$ \\
\hline Govt. cons. and gross investment & $1985: 4$ & 1.014 & -0.447 & $\mathbf{- 2 . 1 7 4}$ & 0.559 & 0.33 & 0.00 & 20.1 \\
Federal & $1982: 4$ & 2.326 & 0.689 & 0.964 & 1.296 & 0.40 & 0.00 & 8.5 \\
Nondefense & $1981: 1$ & 2.189 & 1.475 & 1.421 & 1.674 & -0.33 & 0.78 & 5.9 \\
Consumption expenditures & $1984: 2$ & 6.109 & -2.881 & -1.069 & 0.528 & -0.43 & 0.64 & 5.0 \\
Gross investment & $1983: 3$ & 20.059 & -3.323 & -0.674 & 0.834 & -0.71 & 0.25 & 0.9 \\
National defense & $1985: 1$ & 3.253 & 1.838 & 1.526 & 1.565 & 0.53 & 0.00 & 2.6 \\
Consumption expenditures & $1986: 1$ & 1.979 & 2.944 & 3.217 & 2.488 & 0.61 & 0.00 & 2.2 \\
Gross investment & $1981: 2$ & 176.301 & -147.290 & $\mathbf{- 3 . 4 7 9}$ & 0.165 & -0.30 & 0.00 & 0.4 \\
State and local & $1986: 1$ & 0.946 & -0.685 & $\mathbf{- 3 . 2 3 6}$ & 0.276 & 0.25 & 0.05 & 11.6 \\
Consumption expenditures & $1986: 1$ & 0.171 & -0.061 & -1.378 & 0.642 & 0.62 & 0.00 & 9.1 \\
Gross investment & $1982: 1$ & 21.252 & -17.291 & $\mathbf{- 2 . 8 0 5}$ & 0.186 & 0.00 & 0.23 & 2.4 \\
\hline
\end{tabular}

Notes for Table 4 and 5: Data in all subsectors but change in private inventory are from the National Income and Accounts Table 1.5.3. Data of change in private inventory is from Table 1.4.6. The last column "\%" denotes the percentage share of each subsector in GDP at the time 1984:1. Entries in bold indicate a statistically significant decline using the 5\% "supremum" critical value of -2.115 obtained from the first row of Table 1 . 
Table 6: Estimated Break Dates for Some Important Subsectors and the Corresponding Posterior Odds Ratios

\begin{tabular}{|c|c|c|c|c|c|c|c|c|c|c|c|c|c|c|}
\hline Date & GDP & Motor & $\begin{array}{l}\text { Dur_- } \\
\text { Other }\end{array}$ & House & $\begin{array}{l}\text { Med } \\
\text { Care }\end{array}$ & $\begin{array}{l}\text { Ser_- } \\
\text { Other }\end{array}$ & $\begin{array}{c}\text { Non } \\
\text { resi }\end{array}$ & Resi & $\begin{array}{c}\text { Ex } \\
\text { Goods }\end{array}$ & $\begin{array}{c}\text { Exp_ }_{-} \\
\text {Ser }\end{array}$ & $\begin{array}{c}\text { Im- } \\
\text { Goods }\end{array}$ & $\begin{array}{c}\mathrm{Imp} \\
\text { Ser }\end{array}$ & $\begin{array}{l}\text { Fed_Nat } \\
\text { Def_Inv }\end{array}$ & $\begin{array}{l}\text { State_L } \\
\text { ocal_Inv }\end{array}$ \\
\hline $1 / 1 / 1981$ & 0.03 & 0.03 & 0.11 & 0.00 & 0.10 & 0.03 & 0.09 & 0.01 & 0.03 & 0.00 & 0.00 & 0.01 & 0.60 & 0.00 \\
\hline 4/1/1981 & 0.08 & 0.04 & 0.10 & 0.00 & 0.07 & 0.02 & 0.07 & 0.00 & 0.02 & 0.00 & 0.00 & 0.01 & 1.00 & 0.02 \\
\hline 7/1/1981 & 0.07 & 0.03 & 0.08 & 0.01 & 0.07 & 0.02 & 0.06 & 0.02 & 0.11 & 0.00 & 0.00 & 0.01 & 0.47 & 0.02 \\
\hline 10/1/1981 & 0.13 & 0.10 & 0.85 & 0.01 & 1.00 & 0.02 & 0.05 & 0.02 & 0.07 & 0.00 & 0.00 & 0.01 & 0.28 & 0.01 \\
\hline 1/1/1982 & 0.31 & 0.07 & 0.76 & 0.01 & 0.70 & 0.01 & 0.13 & 0.02 & 0.41 & 0.00 & 0.01 & 0.00 & 0.15 & 1.00 \\
\hline 4/1/1982 & 0.24 & 0.05 & 0.53 & 0.01 & 0.65 & 0.02 & 0.26 & 0.01 & 0.31 & 0.00 & 0.01 & 0.01 & 0.57 & 0.38 \\
\hline 7/1/1982 & 0.24 & 0.02 & 1.00 & 0.01 & 0.31 & 0.02 & 0.25 & 0.00 & 0.55 & 0.00 & 0.01 & 0.01 & 0.34 & 0.61 \\
\hline 10/1/1982 & 0.14 & 0.05 & 0.82 & 0.01 & 0.29 & 0.16 & 0.19 & 0.34 & 1.00 & 0.00 & 0.02 & 0.00 & 0.37 & 0.06 \\
\hline 1/1/1983 & 0.11 & 0.03 & 0.56 & 0.01 & 0.14 & 0.18 & 0.15 & 1.00 & 0.75 & 0.00 & 0.02 & 0.00 & 0.18 & 0.03 \\
\hline $4 / 1 / 1983$ & 0.93 & 0.07 & 0.32 & 0.00 & 0.06 & 0.17 & 0.15 & 0.82 & 0.47 & 0.00 & 0.10 & 0.01 & 0.15 & 0.02 \\
\hline 7/1/1983 & 0.90 & 0.07 & 0.45 & 0.07 & 0.03 & 0.20 & 0.36 & 0.77 & 0.20 & 0.00 & 0.14 & 0.01 & 0.09 & 0.03 \\
\hline $10 / 1 / 1983$ & 0.89 & 0.07 & 0.49 & 0.06 & 0.01 & 0.15 & 1.00 & 0.43 & 0.17 & 0.00 & 0.12 & 0.00 & 0.09 & 0.01 \\
\hline 1/1/1984 & 1.00 & 0.06 & 0.55 & 0.06 & 0.01 & 0.20 & 0.73 & 0.17 & 0.17 & 0.01 & 0.50 & 0.07 & 0.05 & 0.03 \\
\hline $4 / 1 / 1984$ & 0.78 & 0.04 & 0.51 & 0.05 & 0.02 & 0.14 & 0.69 & 0.06 & 0.09 & 0.01 & 0.41 & 0.07 & 0.03 & 0.02 \\
\hline 7/1/1984 & 0.39 & 0.02 & 0.42 & 0.40 & 0.01 & 0.46 & 0.49 & 0.04 & 0.06 & 0.01 & 0.12 & 0.07 & 0.02 & 0.04 \\
\hline $10 / 1 / 1984$ & 0.18 & 0.01 & 0.35 & 0.35 & 0.01 & 0.45 & 0.36 & 0.02 & 0.03 & 0.01 & 0.05 & 0.07 & 0.13 & 0.02 \\
\hline 1/1/1985 & 0.08 & 0.02 & 0.25 & 0.49 & 0.00 & 1.00 & 0.29 & 0.01 & 0.05 & 0.01 & 0.78 & 0.06 & 0.07 & 0.01 \\
\hline $4 / 1 / 1985$ & 0.03 & 0.01 & 0.22 & 0.55 & 0.00 & 0.80 & 0.21 & 0.00 & 0.04 & 0.20 & 0.73 & 0.05 & 0.13 & 0.02 \\
\hline $7 / 1 / 1985$ & 0.05 & 0.03 & 0.15 & 0.45 & 0.00 & 0.50 & 0.30 & 0.00 & 0.03 & 0.01 & 0.52 & 0.18 & 0.11 & 0.01 \\
\hline $10 / 1 / 1985$ & 0.02 & 0.06 & 0.09 & 0.34 & 0.00 & 0.39 & 0.27 & 0.00 & 0.02 & 0.01 & 0.46 & 0.14 & 0.07 & 0.01 \\
\hline 1/1/1986 & 0.01 & 0.04 & 0.06 & 0.41 & 0.00 & 0.40 & 0.30 & 0.00 & 0.01 & 0.51 & 0.43 & 0.13 & 0.04 & 0.02 \\
\hline 4/1/1986 & 0.01 & 0.03 & 0.04 & 0.48 & 0.00 & 0.26 & 0.44 & 0.00 & 0.01 & 0.40 & 1.00 & 0.82 & 0.04 & 0.01 \\
\hline 7/1/1986 & 0.00 & 1.00 & 0.14 & 1.00 & 0.00 & 0.17 & 0.33 & 0.00 & 0.00 & 1.00 & 0.55 & 1.00 & 0.47 & 0.00 \\
\hline $10 / 1 / 1986$ & 0.00 & 0.83 & 0.66 & 0.00 & 0.31 & 0.12 & 0.00 & 0.00 & 0.69 & 0.26 & 0.83 & 0.29 & 0.01 & 0.01 \\
\hline
\end{tabular}


Table 7: Interest Rate Volatility

\begin{tabular}{llcccccc}
\hline \multicolumn{1}{c}{ Series } & \multicolumn{1}{c}{ Date } & $\boldsymbol{\alpha}_{\mathbf{0}}$ & $\gamma_{\mathbf{1}}$ & $\boldsymbol{t}$-stat & $\boldsymbol{h}_{\mathbf{2}} / \boldsymbol{h}_{\mathbf{1}}$ & $\sum \boldsymbol{a}_{\boldsymbol{i}}$ & $\sum \boldsymbol{\alpha}_{\boldsymbol{i}}$ \\
\hline Fed Funds & $1986: 12$ & 0.207 & -0.189 & -2.368 & 0.084 & 0.710 & 0.702 \\
3-mo. T-Bill & $1986: 3$ & 0.124 & -0.109 & -3.635 & 0.012 & 0.533 & 0.758 \\
1-yr. Treas. & $1985: 4$ & 0.211 & -0.183 & -4.024 & 0.132 & 0.427 & 0.490 \\
3-yr. Treas. & $1985: 4$ & 0.191 & -0.139 & -2.842 & 0.275 & 0.255 & 0.248 \\
10-yr. Treas. & $1986: 7$ & 0.140 & -0.090 & -3.674 & 0.356 & 0.151 & 0.140
\end{tabular}


Figure 1: Growth Rates of GDP and Four Key Subsectors

Gross Domestic Product

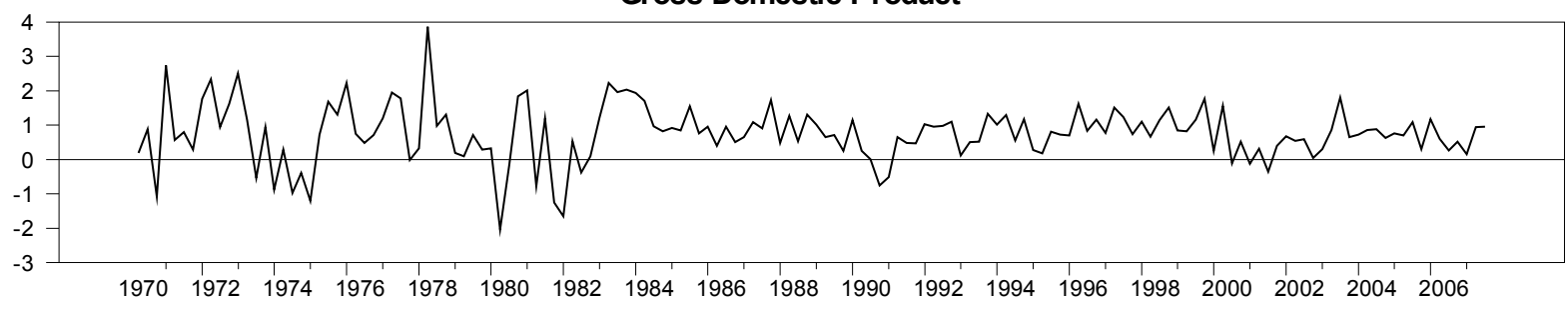

Residential Inv estment

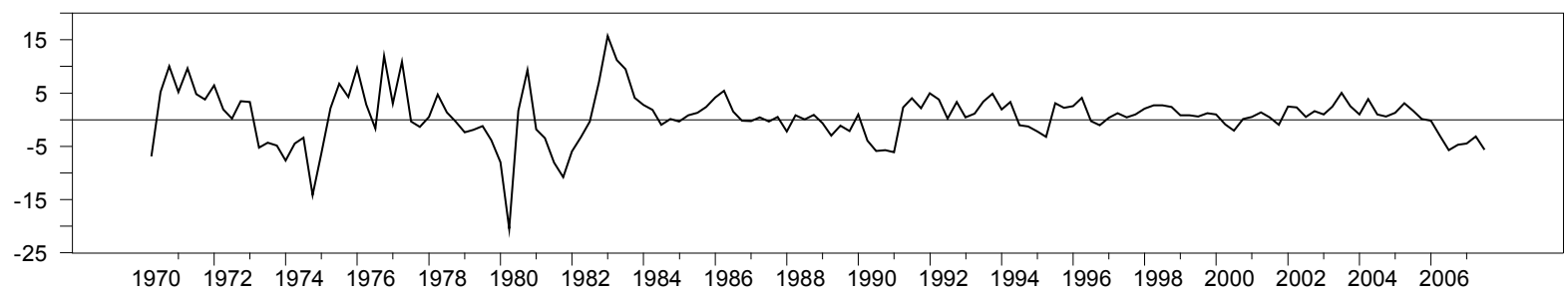

Exports of Goods

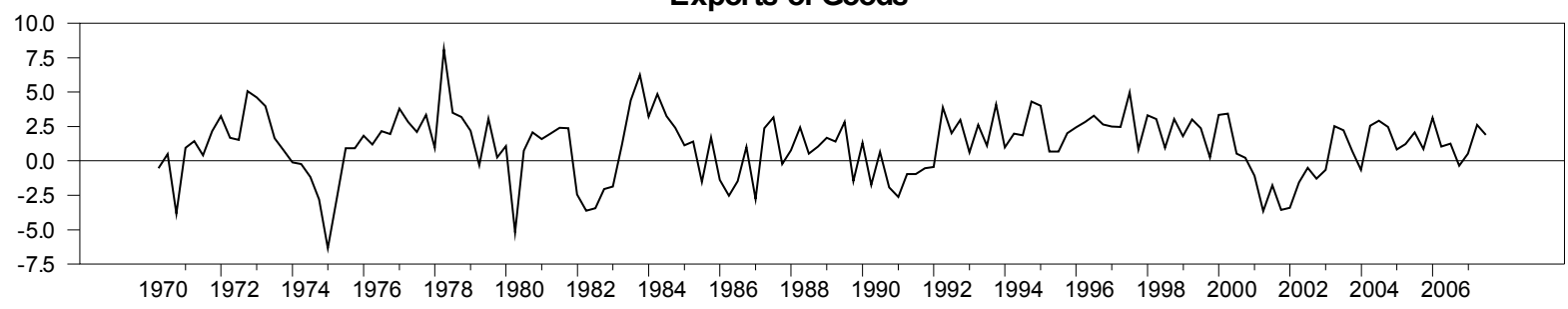

Services

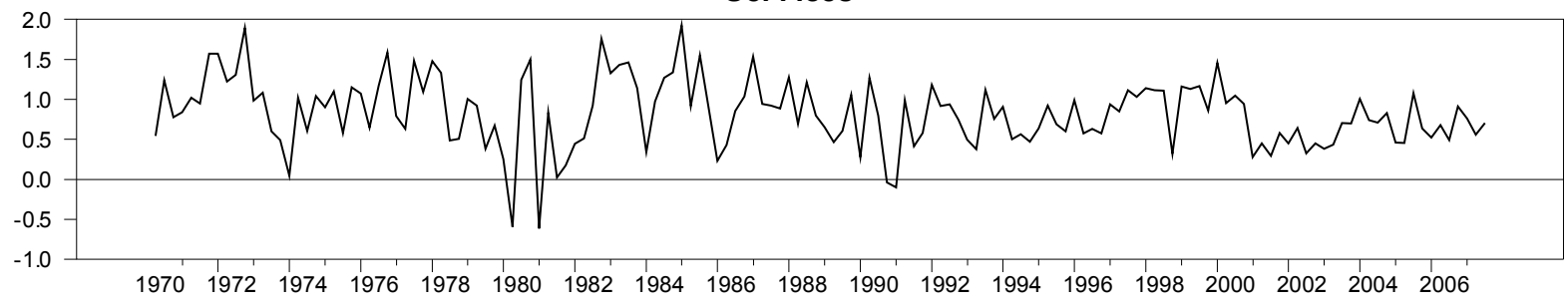

Durable Goods

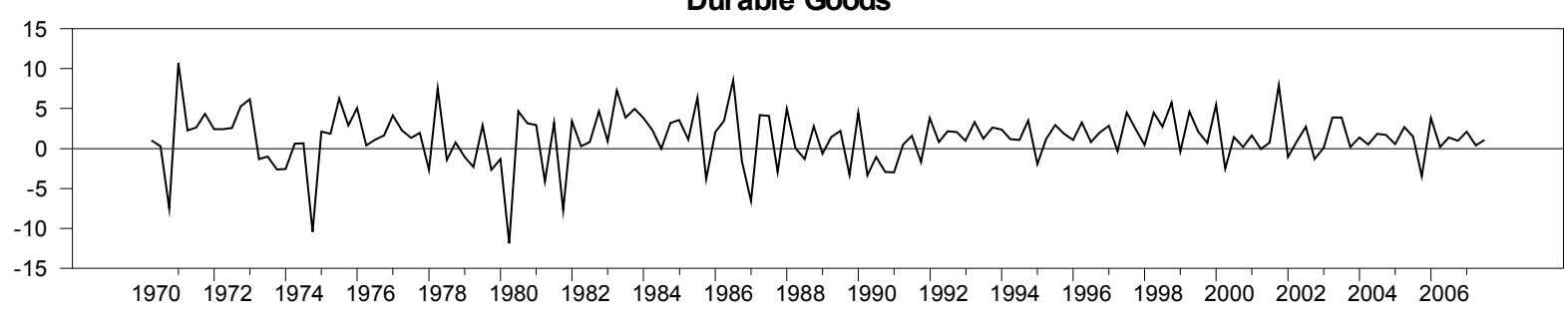




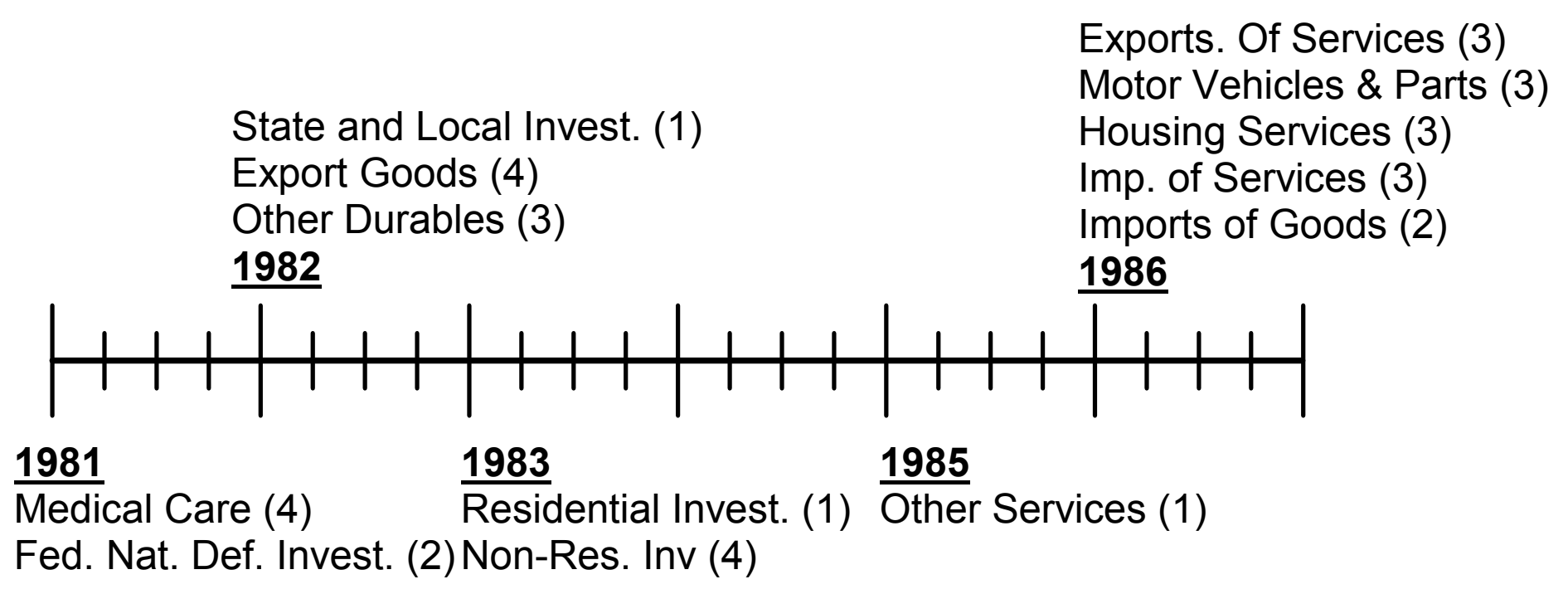


Figure 3: Smoothed Probability of Staying in the High Volatility Regime
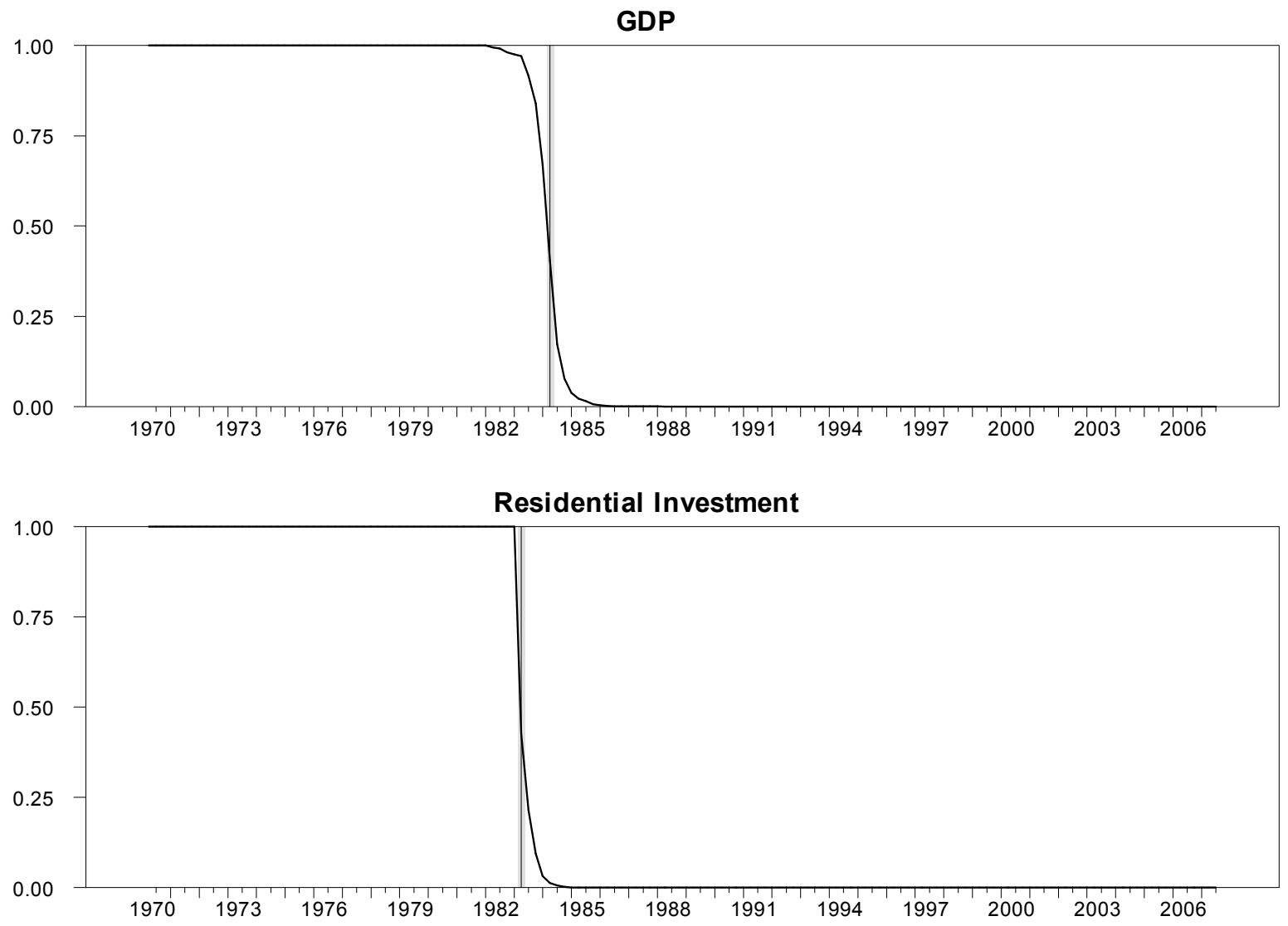

Nonresidential Investment

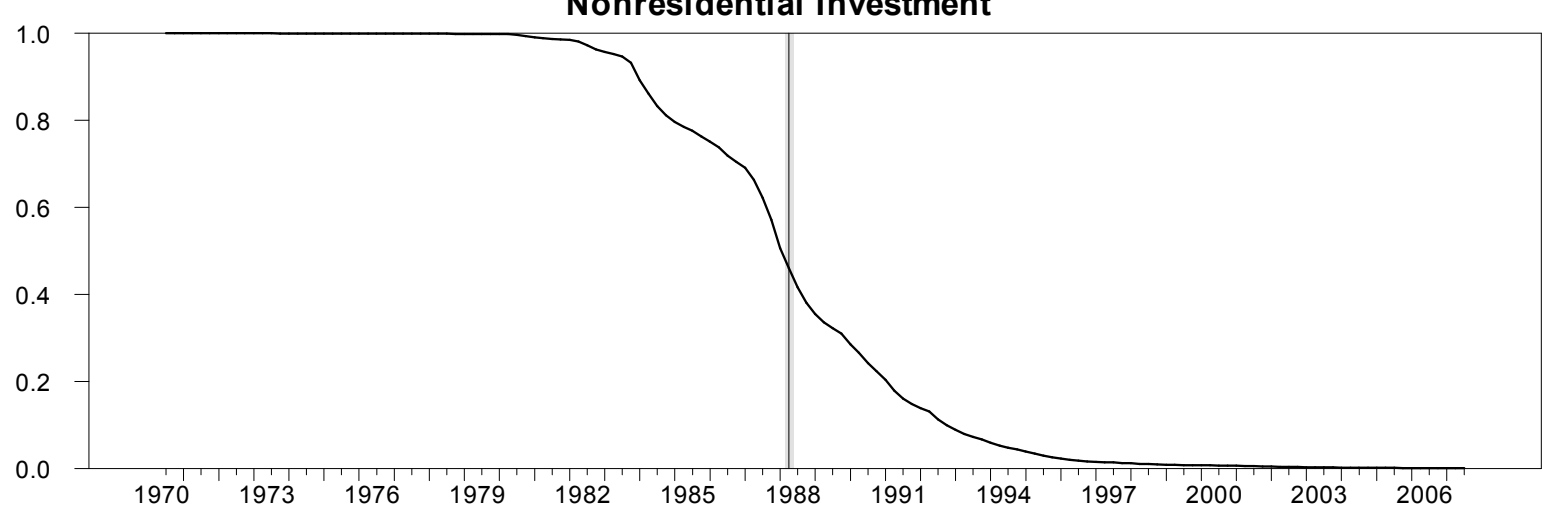




\section{Exported Goods}
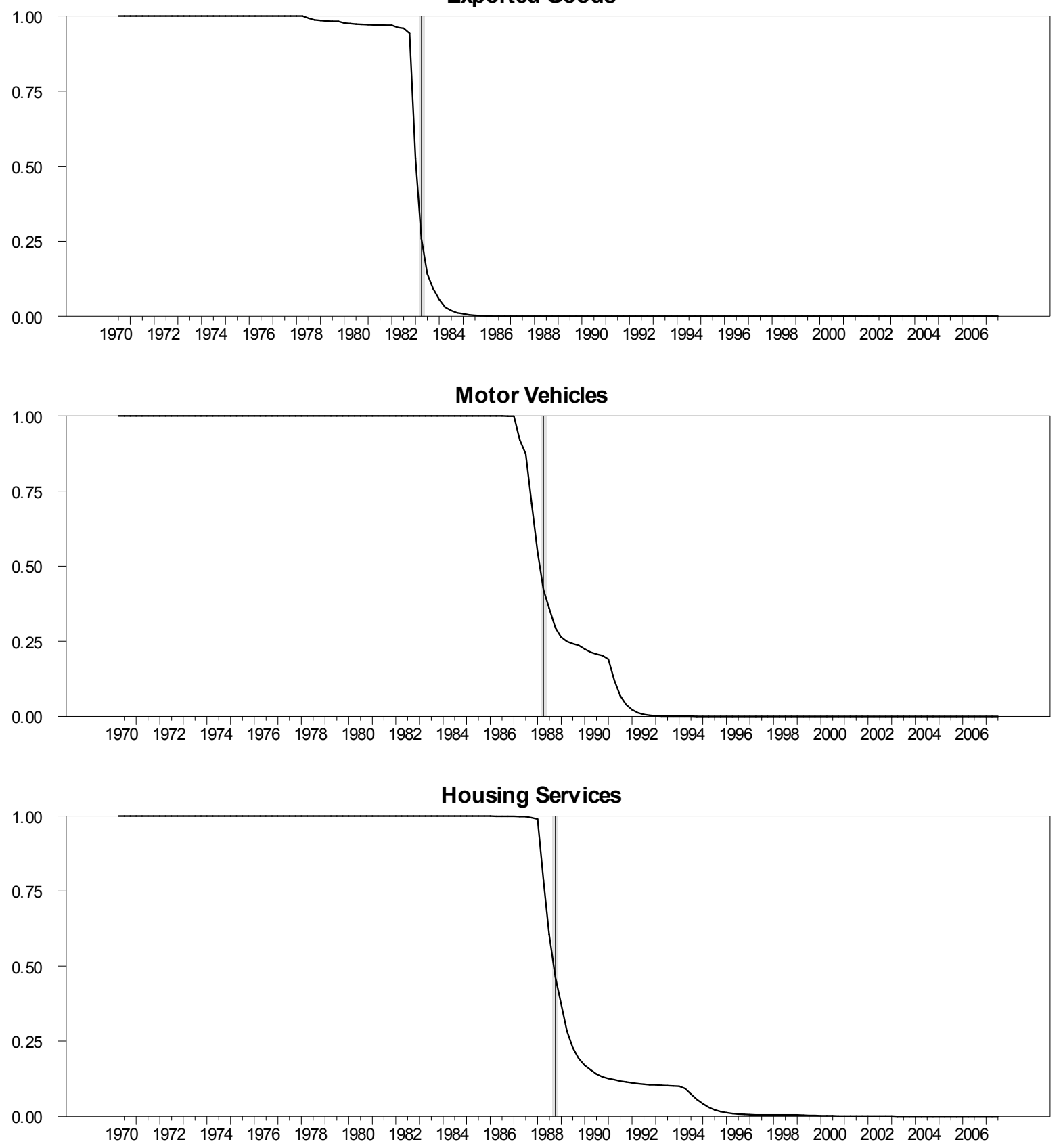

Note: The shaded gridline represents the first quarter in which the probability of staying in the high volatility regime drops below 0.5 . 